\title{
Frontline Treatment of Acute Myeloid Leukemia in Adults Long-Term Results in a Mexican Medical Center
}

\begin{abstract}
Alvarado Ibarra Martha*, Guerra Alarcón Lidia Virginia, Mena Zepeda Verónica, Ortiz Zepeda Maricela, Espitia Ríos Eugenia, Álvarez Vera José Luis, De la Peña Celaya Antonio and López Hernández Manuel Antonio
\end{abstract} Hematology Service, National Medical Center, Mexico

Submission: April 29, 2018; Published: May 15, 2018

*Correspondence Address: Martha Alvarado Ibarra, Hematology Service National Medical Center, ISSSTE, 52005003-14252; Email: normoblasto@gmail.com

\section{Abstract}

Introduction: Acute myeloid leukemias were previously known as a single disease, they are a heterogeneous group of diseases with different morphological characteristics and several genetic alterations that are related to prognosis, in general the five years overall survival for patients with de novo Acute Myeloid Leukemia (AML) is only 25\% according to Surveillance, Epidemiology, and End Results Program (SEER) from United States of America. Standard chemotherapy for this type of leukemia with best results is those schemes based on cytarabine and anthracycline administration achieving Complete Response (CR) rates of $85 \%$.

Objective: To know the Overall Survival (OS) and Relapse-Free Survival (RFS) in patients with de novo AML treated with the protocol named LANOL from ISSSTE”s National Medical Center (NMC) Hematology Service "20 de noviembre".

Patients and methods: A Prospective, Longitudinal, Single-center, single arm trial in patients with de Novo AML including from January 2000 to December 2015, that are candidates to receive intensive chemotherapy from Hematology Service LANOL protocol based on 7-day cytarabine administration at standard dose plus anthracycline according to the Service availability (idarubicin or daunorubicin) for 3 days during the induction phase at the remission and two post-remissions with cytarabine high doses associated to anthracycline and a topoisomerase II inhibitor. Clinical and electronic files were reviewed to consign all the variables.

Results: 204 patients were included, age median was 39 years old (15-60), 115 female and 89 male, the central nervous system (CNS) infiltration at diagnosis was of 13 cases (6\%), baseline leukocytes median was 58.4/ $\mathrm{mm}^{3}$, LDH median was 846 UI and bone marrow blasts median was $51 \%$. Remission was $78 \%$, death at induction was $18 \%, 88$ patients received daunorubicin and 116 idarubicin, without statistical difference when analyzing the baseline data $(p=0.54)$, the univariate and multivariate analysis for RFS had influence from age, albumin and peripheral blood blasts ( $\mathrm{p}<0001$ ), EFS at 16 years of follow-up was $37 \%$ and OS was $39 \%$, there was no statistically significant difference for EFS by anthracycline type $\mathrm{p}=0.16,98 \%$ of patients entered into a febrile neutropenia program and success was $86 \%$, there were 12 deaths due hemorrhage.

Conclusion: AML occurs at earlier ages, from 10 to 15 years before that reported for western population with prevalence of female gender. OS and RFS is similar to that reported in international literature without difference according to the anthracycline type, mortality was mainly associated to infections and secondarily due hemorrhages.

Keywords: Acute myeloid leukemia; Remission; Relapse-free survival; Overall survival; Anthracycline

\section{Introduction}

A series of trials for Cancer and Group B Leukemia before 1985 stated the $7+3$ chemotherapy scheme as standard for the induction of patients diagnosed with de Novo Acute Myeloid Leukemia [1-3]. Over time the anthracyclines dose has been evaluated to give better results, for example, daunorubicin at $45 \mathrm{mg} / \mathrm{m}^{2}$ dose per day (DNR 45) was superior to DNR $30 \mathrm{mg} / \mathrm{m}^{2}$ per day (DNR 30) in the $7+3$ scheme in order to achieve complete remission (CR) in patients under 60 years old. Increasing the ARA $\mathrm{C}$ dose at $200 \mathrm{mg} / \mathrm{m}^{2}$ per day extending the infusion period to 10 days $(10+3)$ or adding oral thioguanine $100 \mathrm{mg} / \mathrm{m}^{2}$ twice a day on days 1 to 7 did not add any improvement in CR ranges from the $7+3$ scheme with a mean of $53 \%$ in patients older than 60 years old, these results are higher for younger patients, between $75 \%-84 \%$. The post-remission therapy value at cytarabine high doses was early recognized, based on that achieving a CR with current chemotherapy is not enough to cure AML.

\section{Objectives}

\section{General objective}

To know the overall survival and disease-free survival in patients with de Novo AML treated according to protocol LANOL from the NMC Hematology Service 20 de Noviembre. 


\section{Specific objectives}

i. To know the complete remission rates with the chemotherapy scheme from the Hematology Service names LANOL.

ii. To know the relapse rates.

iii. To know the mortality frequency per chemotherapy cycle.

iv. To know the percentage of patients with hematopoietic precursors transplant.

v. To know the most frequent AML type at the Service.

\section{Patients and Methods}

\section{Prospective, longitudinal, single-center, single-arm trial}

Patients with de Novo Acute Myeloid Leukemia diagnosis were included since January 2000 to December 2015 receiving intensive chemotherapy according to LANOL protocol from NMC Hematology Service "20 de Noviembre" older than 15 years old with de Novo AML diagnosis candidates to intensive chemotherapy according to current LANOL protocol from Service, having LVEF $>50 \%$, Karnofsky $>60 \%$, Creatinine $<2$ $\mathrm{mg} / \mathrm{dL}$ and Total Bilirubin $<2 \mathrm{mg} / \mathrm{dL}$ [4-7].

During induction cytarabine was administrated at a $100 \mathrm{mg} /$ $\mathrm{m}^{2}$ dose as a 24-day continuous infusion, simultaneously, idarubicin was administrated at $12 \mathrm{mg} / \mathrm{m}^{2}$ dose or daunorubicin at $45 \mathrm{mg} / \mathrm{m}^{2}$ dose during 3 days as a 1 -hour infusion according to the Service availability. Failure patients received a second induction with cytarabine at high dose [8-13]. During postremissions, they received cytarabine at $1.5 \mathrm{gr} / \mathrm{m}^{2}$ dose every 12 hours during 4 days together with etoposide $250 \mathrm{mg} / \mathrm{m}^{2}$ during 2 days at the first post-remission and in second post-remission cytarabine at the same dose together with daunorubicin at $45 \mathrm{mg} / \mathrm{m}^{2}$ during 2 days or idarubicin. The response evaluation was performed on day 28 post-chemotherapy. The complete chemotherapy scheme is described in annex 1.

\section{Statistical Analysis}

Nominal variables were expressed in percentage, numeric variables were expressed as mean, median, minimum and maximum [14-18]. Student's T was used to compare numeric variables and was confirmed with ANOVA table; Squared Chi was used to compare nominal variables and was confirmed using Cochran and Mantel-Haenszel. The univariate and multivariate analysis were performed with $95 \%$ confidence interval. OS, RFS and EFS were analyzed by Kaplan-Meier. A p-value $<0.05$ was considered as statistically significant [19-21]. For statistical tests and survival curves construction the statistical program SPSS 22.0 (SPSS Inc. Chicago, Illinois, USA) was used.

\section{Terms Definition}

\section{Acute myeloid leukemia}

A type of cancer characterized by clonal proliferation of hematopoietic system cells (blasts), with abnormal differentiation, ability to infiltrate the bone marrow, blood and other tissues [22-24].

\section{Remission}

Less than $5 \%$ of blasts in bone marrow, with normal cellularity at the end of induction with normal hematopoiesis reconstitution and disappearance of clinical manifestations attributed to the disease.

\section{Overall survival (OS)}

Time elapsed since the disease diagnosis until the patient's death.

\section{Event-free survival (EFS)}

Time elapsed since the disease diagnosis until death or relapse.

\section{Relapse-free survival (RFS)}

Time elapsed since achieving remission until new appearance of the disease.

\section{Relapse}

More than $5 \%$ of blasts in bone marrow after achieving the remission or extra-myeloid infiltration data after achieving the remission.

\section{Failure}

More than $5 \%$ of blasts in bone marrow at the end of Induction.

\section{Extra-myeloid infiltration}

Blasts infiltration to other organs than bone marrow.

\section{Results}

204 patients with AML diagnosis were analyzed treated with LANOL scheme in 16 years, when studying the general population characteristics, it was seen that age median was 39 years old (15 to 60 years old); $57 \%$ of patients were female and $43 \%$ male, the extra-myeloid infiltration was $19 \%$ (CNS, liver, spleen, skin and mucous), from these $6 \%$ was CNS, as shown in Table 1. According to AML type, the most frequent were: AML M2 and M4 with 34\% and 31\%, respectively (Table 2). 82\% of patients had a functional status measured by Karnofsky greater than $80 \%$ (Table 3). In relation to baseline laboratory studies, the leukocytes median was $58,400 / \mathrm{mm}^{3}$ and the peripheral blood (PB) blasts and bone marrow (BM) was 43\% and 51\% respectively, the remaining baseline studies are shown in Table 4. 


\section{Cancer Therapy \& Oncology International Journal}

Table 1: Baseline Data.

\begin{tabular}{|c|c|}
\hline Data & Results \\
\hline Entries years ( $\mathrm{n}=)$ & 204 \\
\hline Age (median) & 39 years old (15 to 60) \\
\hline Gender M/F (n=) & $89 / 115$ \\
\hline CNS infiltration ( $=$ ) & $13(6 \%)$ \\
\hline Extra-myeloid infiltration & $23(13 \%)$ \\
\hline Hepatomegaly ( $\mathrm{n}=)$ & $51(25 \%)$ \\
\hline Splenomegaly $(\mathrm{n}=)$ & $51(25 \%)$ \\
\hline
\end{tabular}

M: Male; F: Female; CNS: Central Nervous System.

Table 2: FAB classification $(n=204)$.

\begin{tabular}{|c|c|}
\hline Data & Result (n=) \\
\hline M0 & $1(<1 \%)$ \\
\hline M1 & $21(10 \%)$ \\
\hline M2 & $71(35 \%)$ \\
\hline M4 & $64(31 \%)$ \\
\hline M5 & $27(14 \%)$ \\
\hline M6 & $15(7 \%)$ \\
\hline M7 & $5(2 \%)$ \\
\hline
\end{tabular}

Table 3: Karnofsky.

\begin{tabular}{|c|c|}
\hline Data & Result $(\mathrm{n}=)$ \\
\hline $40 \%$ & $4(2 \%)$ \\
\hline $60 \%$ & $15(7 \%)$ \\
\hline $70 \%$ & $17(9 \%)$ \\
\hline $80 \%$ & $21(10 \%)$ \\
\hline $90 \%$ & $52(25 \%)$ \\
\hline $100 \%$ & $95(47 \%)$ \\
\hline
\end{tabular}

Table 4: Baseline laboratory studies.

\begin{tabular}{|c|c|}
\hline Data & Result \\
\hline Hematocrit \% (median) & $24(13-39)$ \\
\hline Leukocytes $/ \mathrm{mm}^{3}$ (median) & $58.4(0.2-756)$ \\
\hline Platelets $/ 10$ (median) & $43(4-600)$ \\
\hline Creatinine mg/Dl (median) & $0.8(0.4-2.9)$ \\
\hline Albumin gr/dL (median) & $3.1(1.2-4.4)$ \\
\hline LDH UI (median) & $846(103-7800)$ \\
\hline ALT U (median) & $42(5-279)$ \\
\hline AST (median) & $35(7-234)$ \\
\hline PB Blasts (median) & $43(0-98)$ \\
\hline BM Blasts (median) & $51(20-100)$ \\
\hline
\end{tabular}

ALT: Aspartate Alaninotransferase; AST: Aspartate Aminotransferase; LDH: Lactic Dehydrogenase, PB: peripheral blood; BM: Bone Marrow

The most frequently markers found in the immunophenotype are shown in Table 5 showing predominance of Myeloperoxidase, HLA DR, CD34, CD 33 and CD 13. Cytogenetic analysis was performed for $46 \%$ of case (95 patients), the most common were normal karyotype, $\mathrm{t}(8 ; 21)$ and inv(16), FLT3 mutation could only be performed in 4 patients (Table 6). All patients received an induction scheme at remission with the usual $7+3$, daunorubicin was administrated in 88 patients and idarubicin in 116 . Remission rate was $78 \%$, mortality was $18 \%(15 \%$ associated to infection and 3\% due hemorrhage) and $8 \%$ failure; all failure patients ( 9 patients) received a second induction at the remission with cytarabine high dose, from which 4 (44\%) achieved remission and the rest deceased. $98 \%$ of patients entered into a febrile neutropenia program and there was success for $86 \%$, tumor lysis was $9 \%$ and G-I-II hepatic toxicity in $17 \%$ [25-27].

Table 5: Expression frequency of surface antigens.

\begin{tabular}{|c|c|}
\hline Data & Result (\%) \\
\hline CD34 & 76 \\
\hline HLA DR & 80 \\
\hline MPO & 86 \\
\hline CD33 & 86 \\
\hline CD117 & 68 \\
\hline CD14 & 55 \\
\hline CD11c & 59 \\
\hline CD11b & 48 \\
\hline CD71 & 25 \\
\hline CD13 & 80 \\
\hline CD64 & 34 \\
\hline CD15 & 62 \\
\hline
\end{tabular}

Table 6: Karyotype $(n=95)$ and mutations $(n=4)$.

\begin{tabular}{|c|c|}
\hline Data & Result \\
\hline Normal karyotype $(\mathrm{n}=)$ & 39 \\
\hline $\mathrm{t}(8 ; 21)(\mathrm{n}=)$ & 29 \\
\hline $\operatorname{inv}(16)(\mathrm{n}=)$ & 15 \\
\hline $\mathrm{t}(16 ; 16)(\mathrm{n}=)$ & 3 \\
\hline $\mathrm{t}(9 ; 11)(\mathrm{n}=)$ & 2 \\
\hline $\begin{array}{c}\text { Complex (more than } 3 \\
\text { alterations) }(\mathrm{n}=)\end{array}$ & 7 \\
\hline FLT3 ITD mutation $(\mathrm{n}=)$ & 2 \\
\hline FLT3 TKD mutated mutation $(\mathrm{n}=)$ & 2 \\
\hline
\end{tabular}

164 patients received the first post-remission and mortality was $16 \% ; 139$ patients received a second post-remission and mortality was 17\%, 28 patients fulfilled the requirements for bone marrow transplant, from which 18 were allogenic and 10 autologous (Tables $7 \&$ 8). When comparing the baseline data by anthracycline type used, there was no statistically significant difference with each variable. When evaluating the remission by anthracycline type there was also no statistically significant difference $\mathrm{p}=0.10$, neither for the relapses number $\mathrm{p}=0.72$, and deaths were similar $\mathrm{p}=0.86$ (Table 9). 


\section{Cancer Therapy \& Oncology International Journal}

Table 7: Induction treatment results $(n=204)$.

\begin{tabular}{|c|c|}
\hline Data & Result \\
\hline Anthracycline & $88(43 \%)$ \\
\hline Daunorubicin (n=) & $116(57 \%)$ \\
\hline Idarubicin (n=) & $160(78 \%)$ \\
\hline Induction & $9(8 \%)$ \\
\hline Remission (n=) & $35(18 \%)$ \\
\hline Failure (n=) & $\mathbf{9}$ \\
\hline Death (n=) & 4 \\
\hline Second Induction (n=) & 5 \\
\hline Remission (n=) & \\
\hline Death (n=) & \\
\hline
\end{tabular}

Table 8: Post-Induction Results.

\begin{tabular}{|c|c|}
\hline Data & Result \\
\hline $1^{\text {st }}$ post-remission ( $\left.\mathrm{n}=\right)$ & 164 \\
\hline Death (n=) & $25(16 \%)$ \\
\hline $2^{\text {nd }}$ post-remission (n=) & 139 \\
\hline Death (n=) & $24(17 \%)$ \\
\hline Bone marrow transplant & 28 \\
\hline Allogenic (n=) & 18 \\
\hline Autologous (n=) & 10 \\
\hline Relapse $(\mathrm{n}=)$ & 41 \\
\hline
\end{tabular}

Table 9: Baseline Results by Anthracycline type $(n=204)$.

\begin{tabular}{|c|c|c|c|}
\hline Data & Daunorubicin (n = 88) & Idarubicin (n = 116) & 0.49 \\
\hline Mean age (years) & 39 & 41 & 0.39 \\
\hline Gender M/F (n=) & $40 / 48$ & $54 / 62$ & 0.51 \\
\hline Leukocytes (median) & 56,000 & 58,000 & 0.47 \\
\hline Hematocrit (median) & $25 \%$ & $24 \%$ & 0.54 \\
\hline Platelets (median) & 39,000 & 42,000 & 0.44 \\
\hline PB Blasts (median) & 40 & 43 & 0.32 \\
\hline BM Blasts (median) & 55 & 48 & 0.29 \\
\hline LDH (median) & 739 & 857 & 0.11 \\
\hline Albumin (median) & 3 & 3.3 & 0.09 \\
\hline Normal karyotype (n=) & 14 & 25 & 0.12 \\
\hline $\mathrm{t}(8 ; 21)$ (n=) & 12 & 17 & 0.46 \\
\hline inv(16) (n=) & 5 & 3 & 0.33 \\
\hline $\mathrm{t}(6 ; 16)(n=)$ & 0 & 0 & 0.12 \\
\hline $\mathrm{t}(9 ; 11)(\mathrm{n}=)$ & 2 & 5 & 0.25 \\
\hline Complex (3 or more alterations) & $(\mathrm{n}=)$ & & \\
\hline
\end{tabular}

M: Male; F: Female; LDH: Lactic Dehydrogenase; PB: Peripheral Blood; BM: Bone Marrow

When performing the univariate and multivariate analysis to know the prognosis influence on RFS, it was found that an age above 45 years old, as well as albumin below $2.5 \mathrm{gr} / \mathrm{dL}, \mathrm{PB}$ blasts presence and mid/high cytogenetic risk were unfavorable factors $\mathrm{p}<0.01$ (Figures 1-3). No prognosis influence was found with gender, leukocytes count and LDH ( $p>0.16)$ (Table 10). 


\section{Cancer Therapy \& Oncology International Journal}

Fig. 1A Event-Free Survival

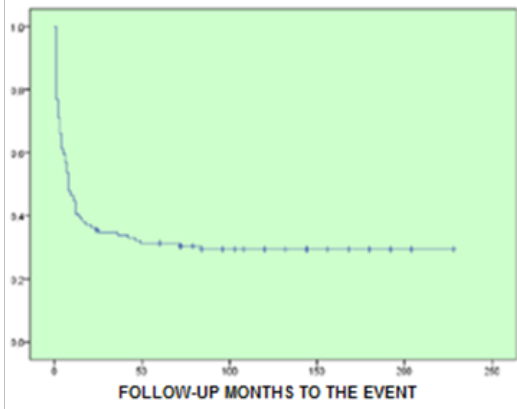

Fig. 1B Overall Survival

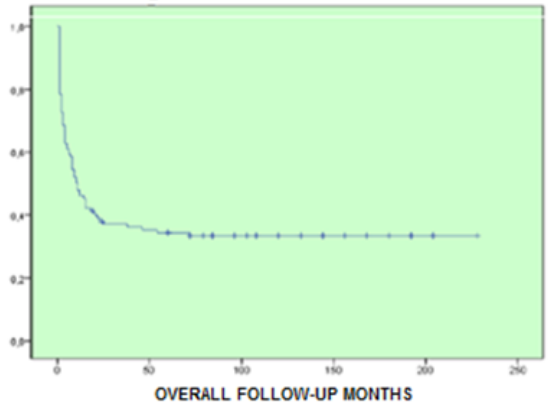

Figure 1: EFS at follow-up of 16 years was $37 \%$ and OS was $39 \%$.

Fig. 2 Event-Free Survival by Anthracycline

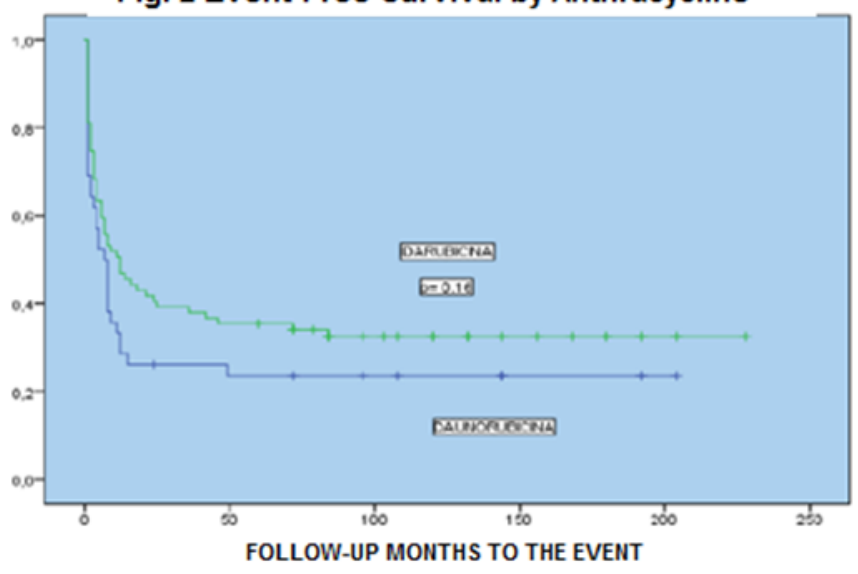

Figure 2:The EFS analysis by anthracycline type did not find a statistically significant difference $(p=0.16)$.
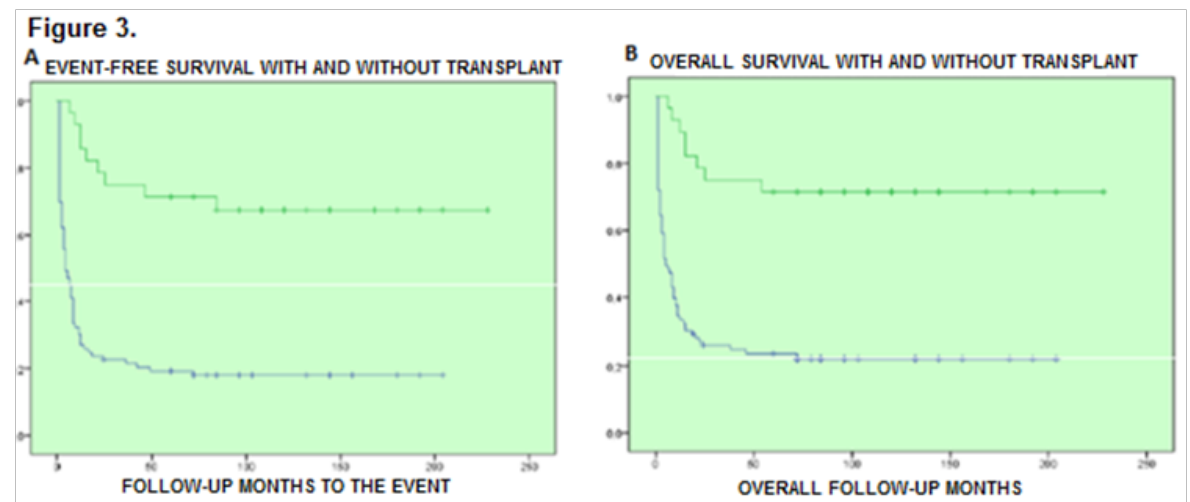

Figure 3: When analyzing the OS of patients subjected to TMO in the 16-year follow-up it was $75 \%$ and from those without transplant was $30 \%, p=0.003$.

Table 10: Univariate and Multivariate Analysis of Relapse-Free Survival.

\begin{tabular}{|c|c|c|c|c|}
\hline \multirow{2}{*}{ Data } & \multirow{2}{*}{ Univariate HR 95\% CI } & \multirow{2}{*}{$\mathbf{p}=$} & Multivariate HR & \multirow{2}{*}{$\mathbf{p}=$} \\
\hline & & & $95 \% \mathrm{CI}$ & \\
\hline Age $>45$ years old & $1.35(1.08-1.69)$ & 0.004 & $1.45(1.13-1.89)$ & 0.04 \\
\hline Gender M/F & $1.61(1.19-2.17)$ & 0.02 & $1.41(1.09-1.83)$ & 0.16 \\
\hline Leukocytes $>30,000 / \mathrm{mm}^{3}$ & $0.73(0.46-1.16)$ & 0.018 & $1.7(1.01-2.86)$ & 0.05 \\
\hline
\end{tabular}




\section{Cancer Therapy \& Oncology International Journal}

\begin{tabular}{|c|c|c|c|c|}
\hline LDH > 500UI & $1.22(0.92-1.61)$ & 0.17 & $0.94(0.75-1.17)$ & 0.56 \\
\hline PB Blasts (\%) & $1.61(1.19-2.17)$ & 0.002 & $2.71(2.17-3.38)$ & $<0.001$ \\
\hline $\begin{array}{c}\text { Low vs. mid/high } \\
\text { cytogenetic risk }\end{array}$ & $0.63(0.35-1.13)$ & 0.012 & $3.36(1.94-3.84)$ & 0.02 \\
\hline
\end{tabular}

M: Male; F: Female; LDH: Lactic dehydrogenase.

\section{Discussion}

Acute Myeloid Leukemias were previously known as a single disease, they are a heterogeneous group of diseases with prognosis linked to its genetic profile [28-31], therefore, the description of the disease characteristics in our population, as well as the outcomes in terms of survival and treatment response are highly relevant, in order to develop new treatment approaches. In this document we present the evidence related to AML epidemiology characteristics at ISSSTE's National Medical Center Hematology Service "Hospital 20 de Noviembre", as well as the survival analysis of patients treated at this center since 2000 until now. Actually, the disease is classified by integrating the genetic information into morphology, immunophenotype and clinical presentation [32], however, genetic analysis is a poor accessibility test, therefore the classification based on morphological and cytochemical characteristics of leukemia cells are still adopted by most Latin American centers [33,34]. Therefore, the AML information presented was classified by FAV and anthracycline type used for initial treatment of patients.

AML represents $1.2 \%$ of new cancer cases reported in USA, with a men and women incidence of 4.1 cases per 100,000 inhabitants, diagnosis median age is 67 years old. In our analysis we saw a mean age for diagnosis of 39 years old, varying from 15 to 64 years old, these data are consistent with that previously reported in literature for Mexican population, which varies from 32 to 44 years old [35-37]. In relation to gender, western literature reports an higher incidence for men in relation to women, we reported a prevalent female population, $57 \%$ versus $43 \%$ of men; when evaluating the AML type by FAB classification excluding M3, the most frequent AML was M2 with 36\%, gender and AML type incidence data are similar to that previously reported in literature, this information is relevant for Hispanic population, as shows an earlier onset of the disease, and prevalence of female gender, future trials targeting the genetic profile study of these patients could offer possible answers of pathophysiology mechanisms behind this clinical presentation [37].

Although actually there are tools such as cytogenetic and molecular abnormalities determination (karyotype), a high leukocytes count is still an independent factor of poor prognosis, mainly in a disease with favorable cytogenetic risk as $\mathrm{t}(8 ; 21)$ and $\mathrm{t}(15 ; 17)$ [38]; from 95 patients with molecular determination, 29 had $t(8 ; 21)$ and none $t(15 ; 17)$, therefore, probably this fact was not reflected in overall survival. The AML immunophenotype has controversial implications in relation to prognosis, the markers with consistent prognosis association are CD13, CD14 and
CD15, as well as the CD11b and CD7 expressions that are clearly associated to poor prognosis, in our cohort, the CD14 expression was documented, in relation to this marker it has been reported its association with poor prognosis in terms of lower range of complete remission, and short overall survival, specifically in the secondary AML to myelodysplastic syndromes group [39].

In relation to the anthracycline used, there is still debate about which gives greater benefit, from published comparative trials, it is suggested a trend to see better response rates with Idarubicin; in our analysis Idarubicin was used in $65 \%$ of cases. Overall, it was seen that the induction response rate with LANOL scheme was $74.4 \%$, in relation to this data, most of the treated population at our hospital is below 60 years old (91.5\%), in this patients group with de novo diagnosis and below 60 years old, complete response rates with the standard " $7+3$ " scheme of $65 \%$ and $75 \%$ have been seen in prospective trials [40-42].

The mean overall survival achieved in our trial treating AML patients with the LANOL scheme was 82 months, generally, literature report overall survival medians of 23-25 months, however, for patients with M2 sub-type AML overall survival means have been reported up to 97.7 months, and for favorable cytogenetic risk patients means over 90 months, which suggests that in our results there was influence form the fact that M2 subtype was the most frequent, and that the peripheral leukocytes below 30,000 in our study was $61 \%$, and both factors were a good prognosis; in addition, there is a need to know the cytogenetic risk of our patients, as these results may suggest that in our population there is a favorable cytogenetic risk group higher to that reported for western population [43-44].

For patients treated with Idarubicin a mean survival of 146 months was reported against 116 months with Daunorubicin, and for patients that received TMO the survival mean was 203 months, at the multivariate analysis it was found a relation between the disease remission and the peripheral blood blasts levels, albumin and ALT, this suggests that patients with normal liver function at diagnosis, and lower peripheral blood blasts count is associated to a better treatment effectiveness with LANOL scheme, it is important to mention that in a meta-analysis asking about the truth of the different anthracyclines effectiveness it has been shown that idarubicin induces to more complete responses $(\mathrm{RR}=1.23 ; 95 \% \mathrm{CI}=1.07-1-41)$ an better overall survival (HR $=0.8895 \% \mathrm{CI}=0.81-0.95)$, in addition to this data it must be considered the anthracycline dose heterogeneity, for example, at our hospital Daunorubicin has been used at $45 \mathrm{mg} / \mathrm{m} 2$ doses, and most centers report experience with a dose of 60 and they even titrate the dose to $90 \mathrm{mg} / \mathrm{m} 2$, with better results for complete 


\section{Cancer Therapy \& Oncology International Journal}

response and survival, however, as previously mentioned, the Mexican population biological factors must be investigated, as the results seen at our hospital using Daunorubicin $45 \mathrm{mg} / \mathrm{m} 2$ suggest that this may be the prospectively evaluated dose [45].

By the other hand, it must be mentioned the essential need of a complete initial evaluation, documenting the patient functional status, in our cohort, the assessment was performed using Karnofsky's scale, finding that about $82 \%$ of patients had a Karnofsky greater to $80 \%$, making a relevant relation with our treatment response and survival results, in previous reports it has been documented that functional status is an important prognosis factor, such that when comparing patients with Karnofsky $>60 \%$ to patients with a lower value in the scale, the overall survival, recurrence-free survival and overall response results are higher with statistically significant differences, this data is consistent with our results stating the functional status as an overall survival prognosis factor [46].

Lastly, when comparing the LANOL scheme therapeutic effectiveness to the results published by the cooperative group from EORTC - GIMEMA a 3-year EFS of $67 \%$ is reported, while PETHEMA foundation reports $51 \%$ of complete remission with schemes containing Idarubicin, and 5-years overall survivals of $52 \%$ in favorable cytogenetic risk groups, and 5-year recurrencefree survival up to $71 \%$ in patients with minimal residual disease lower than $0.01 \%$, these results are consistent to that found in our center, suggesting that our results reproduce the published effectiveness by other groups [47-49].

\section{Conclusion}

In Mexico, the information about persons with AML is scarce, we present the largest series of data from patients with AML analyzed in the country, we can conclude for general population characteristics that the disease is present at earlier ages, from 10 to 15 years before compared to western population, and also there is a higher incidence of the disease in women. This is important as leads to the hypothesis that people with AML in Mexico may have a different genetic profile than western population. From a cytogenetic point of view, overall survival from patients treated with LANOL scheme was similar to that seen in patients with favorable risk, and also agrees with that reported for M2 sub-type, which was the most frequent in our population. This data is important for the Hematology Service as it gives a parameter of expected outcomes in patients with AML treated at our hospital with the LANOL scheme and gives the possibility of new investigations answering questions as the cytogenetic risk of our patients.

Annex 1

\section{Non-lymphoblastic acute leukemia treatment. Lanol}

\author{
Adjunct therapeutic handling \\ i. Ondansetron: $8 \mathrm{mg}$ every $8 \mathrm{hrs}$ \\ ii. Alopurinol $300 \mathrm{mg} /$ day VO.
}

iii. Furosemide, $20 \mathrm{mg}$ per day IV. Adjust the dose according to diuresis and liquid administration.

iv. Saline, $3000 \mathrm{~mL} / \mathrm{m}^{2} \mathrm{sc}$. Adjust according to liquid balance.

v. Potassium IV, $120 \mathrm{~m} \mathrm{Eq/day.} \mathrm{Adjust} \mathrm{according} \mathrm{to}$ controls.

vi. Apply blood pressure control program according to needs.

vii. Bicarbonate and nystatin mouthwashes every $4 \mathrm{hrs}$.

viii. Infection prophylaxis with Ciprofloxacin 250mg VO every $12 \mathrm{hrs}$, Aciclovir 200mg IV every $12 \mathrm{hrs}$, Fluconazol $100 \mathrm{mg}$ IV every $12 \mathrm{hrs}$.

\section{Induction (1.0) day 0}

a. Cytarabine: $100 \mathrm{mg} / \mathrm{m}^{2} \mathrm{sc}$, for 24-hour IV infusion during 7 days (day 1-7).

b. Idarubicin: $12 \mathrm{mg} / \mathrm{m}^{2} \mathrm{sc}$, during 3 days (days $1-3$ ). Daunorubicin may be used, $45 \mathrm{mg} / \mathrm{m} 2 \mathrm{sc}$, days 1 to 3 .

c. FEC G, 300mcg SC from post-chemotherapy day +7 , until neutrophils reach $1,500 / \mu \mathrm{L}$.

\section{Second induction (1.2)}

i. Cytarabine: $1,500 \mathrm{mg} / \mathrm{m}^{2} \mathrm{sc}$ in 4 -hour IV infusion, every $12 \mathrm{~h}$ (days 1 to 3 )

ii. Idarubicin: $12 \mathrm{mg} / \mathrm{m}^{2} \mathrm{sc}$, IV bolus, days 1 and 2 . Daunorubicin may be used, $45 \mathrm{mg} / \mathrm{m} 2 \mathrm{sc}$, days 1 and 2 .

iii. FEC G, 300mcg SC from post-chemotherapy day +7 , until neutrophils reach $1,500 / \mu \mathrm{L}$.

\section{Post-remission (2.1)}

a. Cytarabine: $1,500 \mathrm{mg} / \mathrm{m}^{2} \mathrm{sc}$ in 4 -hour IV infusion, every 12 hours (days 1 to 4 )

b. Etoposide: $250 \mathrm{mg} / \mathrm{m}^{2} \mathrm{sc}$ in 4 -hour IV infusion, days 1 and 2

c. FEC G, 300mcg SC from post-chemotherapy day +7 , until neutrophils reach $1,500 / \mu \mathrm{L}$.

\section{Second post-remission (2.2)}

i. Cytarabine: $1^{\prime} 500 \mathrm{mg} / \mathrm{m} 2 \mathrm{sc}$ in 4-hour IV infusion, every 12 hours (days 1 to 4 ).

ii. Idarubicin: $12 \mathrm{mg} / \mathrm{m}^{2} \mathrm{sc}$, IV bolus, days 1 and 2 . Daunorubicin may be used, $45 \mathrm{mg} / \mathrm{m} 2 \mathrm{sc}$, days 1 and 2 .

iii. FEC G, 300mcg SC from post-chemotherapy day +7 , until neutrophils reach $1,500 / \mu \mathrm{L}$.

\section{Acknowledgement}

Authors thank to the Doctor Mauricio Di Silvio López of the Medical Center and the ISSSTE Foundation. 


\section{Cancer Therapy \& Oncology International Journal}

\section{References}

1. Döhner H, Weisdorf DJ, Bloomfield CD (2015) Acute Myeloid Leukemia. N Engl J Med 373(12): 1136-1152.

2. De Kouchkovsky I, Abdul Hay M (2016) Acute myeloid leukemia: a comprehensive review and 2016 update'. Blood Cancer J 6(7): e441.

3. Santoyo-Sánchez A, Ramos-Peñafiel C, Palmeros-Morgado G, MendozaGarcía E, Olarte-Carrillo I, et al. (2014) Clinical features of acute leukemia and its relationship to the season of the year. Rev Med Inst Mex Seguro Soc 52(2): 176-181.

4. Shah A, Andersson TM, Rachet B, Björkholm M, Lambert PC (2013) Survival and cure of acute myeloid leukaemia in England, 1971-2006: a population-based study. Br J Haematol 162(4): 509-516.

5. Meyers J, Yu Y, Kaye JA, Davis KL (2013) Medicare fee-for-service enrollees with primary acute myeloid leukemia: an analysis of treatment patterns, survival, and healthcare resource utilization and costs. Appl Health Econ Health Policy 11(3): 275-286.

6. Cancer Genome Atlas Research (2013) Genomic and epigenomic landscapes of adult de novo acute myeloid leukemia. N Engl J Med 368(22): 2059-2074.

7. Cho YU, Jang S, Seo EJ, Park CJ, Chi HS, et al. (2015) Preferential occurrence of spliceosome mutations in acute myeloid leukemia with preceding myelodysplastic syndrome and/or myelodysplasia morphology. Leuk Lymphoma 56(8): 2301-2308.

8. Gilliland DG, JD Griffin (2002) The roles of FLT3 in hematopoiesis and leukemia. Blood 100(5): 1532-1542.

9. Takahashi S (2011) Current findings for recurring mutations in acute myeloid leukemia. J Hematol Oncol 4: 36.

10. Cook AM, Li L, Ho Y, Lin A, Li L, et al. (2014) Role of altered growth factor receptor-mediated JAK2 signaling in growth and maintenance of human acute myeloid leukemia stem cells. Blood 123(18): 2826-2837.

11. Lynn RC, Poussin M, Kalota A, Feng Y, Low PS, et al. (2015) Targeting of folate receptor beta on acute myeloid leukemia blasts with chimeric antigen receptor-expressing T cells. Blood 125(22): 3466-3476.

12. Loghavi S, Zuo Z, Ravandi F, Kantarjian HM, Bueso-Ramos C, et al. (2014) Clinical features of de novo acute myeloid leukemia with concurrent DNMT3A, FLT3 and NPM1 mutations. J Hematol Oncol 7: 74.

13. Giles FJ, Borthakur G, Ravandi F, Faderl S, Verstovsek S, et al. (2007) The haematopoietic cell transplantation comorbidity index score is predictive of early death and survival in patients over 60 years of age receiving induction therapy for acute myeloid leukaemia. $\mathrm{Br} \mathrm{J}$ Haematol 136(4): 624-627.

14. Kristinsson SY, Derolf AR, Edgren G, Dickman PW, Björkholm M, et al. (2009) Socioeconomic differences in patient survival are increasing for acute myeloid leukemia and multiple myeloma in sweden. J Clin Oncol 27(12): 2073-2080.

15. Malagola M, Skert C, Vignetti M, Piciocchi A, Martinelli G, et al. (2011) A simple prognostic scoring system for newly diagnosed cytogenetically normal acute myeloid leukemia: retrospective analysis of 530 patients. Leuk Lymphoma 52(12): 2329-2335.

16. Greenwood MJ, Seftel, Richardson C, Barbaric D, Barnett MJ, et al. (2006) Leukocyte count as a predictor of death during remission induction in acute myeloid leukemia. Leuk Lymphoma 47(7): 1245 1252 .

17. Vaughan WP, Kimball AW, Karp JE, Dragon LH, Burke PJ (1981) Factors affecting survival of patients with acute myelocytic leukemia presenting with high wbc counts. Cancer Treat Rep 65(11-12): 10071013.
18. Chen CC, Yang CF, Yang MH, Lee KD, Kwang WK, et al. (2005) Pretreatment prognostic factors and treatment outcome in elderly patients with de novo acute myeloid leukemia. Ann Oncol 16(8): 13661373.

19. Dutcher JP, Schiffer CA, Wiernik PH (1987) Hyperleukocytosis in adult acute nonlymphocytic leukemia: impact on remission rate and duration, and survival. J Clin Oncol 5(9): 1364-1372.

20. Arellano M, Bernal-Mizrachi L, Pan L, Tighiouart M, Souza L, et al. (2011) Prognostic significance of leukopenia at the time of diagnosis in acute myeloid leukemia. Clin Lymphoma Myeloma Leuk 11(5): 427432.

21. Mason KD, Juneja SK, Szer J (2006) The immunophenotype of acute myeloid leukemia: is there a relationship with prognosis? Blood Rev 20(2): 71-82.

22. Li X, Li J, Du W, Zhang J, Liu W, et al. (2011) Relevance of immunophenotypes to prognostic subgroups of age, WBC, platelet count, and cytogenetics in de novo acute myeloid leukemia. APMIS 119(1): 76-84.

23. Mikkael A Sekeres, Bercedis Peterson, Richard K Dodge, Robert J Mayer, Joseph O Moore, et al. (2004) Differences in prognostic factors and outcomes in African Americans and whites with acute myeloid leukemia. Blood 103(11): 4036-4042.

24. Stone RM (2013) Consolidation chemotherapy for adults with AML in first remission: is there a best choice? J Clin Oncol 31(17): 2067-2069.

25. Burnett A, Wetzler M, Löwenberg B (2011) Therapeutic advances in acute myeloid leukemia. J Clin Oncol 29(5): 487-494.

26. Cassileth PA, Begg CB, Bennett JM, Bozdech M, Kahn SB, et al. (1984) A randomized study of the efficacy of consolidation therapy in adult acute nonlymphocytic leukemia. Blood 63(4): 843-847.

27. Schaich M, Parmentier S, Kramer M, Illmer T, Stölzel F, et al. (2013) High-dose cytarabine consolidation with or without additional amsacrine and mitoxantrone in acute myeloid leukemia: results of the prospective randomized AML2003 trial. J Clin Oncol 31(17): 20942102.

28. Weick JK, Kopecky KJ, Appelbaum FR, Head DR, Kingsbury LL, et al. (1996) A randomized investigation of high-dose versus standard-dose cytosine arabinoside with daunorubicin in patients with previously untreated acute myeloid leukemia: a Southwest Oncology Group study. Blood 88(8): 2841-2851.

29. Ohtake S, Miyawaki S, Fujita H, Kiyoi H, Shinagawa K, et al. (2011) Randomized study of induction therapy comparing standard-dose idarubicin with high-dose daunorubicin in adult patients with previously untreated acute myeloid leukemia: the JALSG AML201 Study. Blood 117(8): 2358-2365.

30. Shi P, Zha J, Guo X, Chen F, Fan Z, et al. (2013) Idarubicin is superior to daunorubicin in remission induction of de novo acute myeloid leukemia patients with high MDR1 expression. Pharmacogenomics 14(1): 17-23.

31. Wiernik P, Banks P, Case DJ, Arlin Z, Periman P, et al. (1992) Cytarabine plus idarubicin or daunorubicin as induction and consolidation therapy for previously untreated adult patients with acute myeloid leukemia. Blood 79(2): 313-319.

32. Daniel A Arber, Attilio Orazi, Robert Hasserjian, Jürgen Thiele, Michael J Borowitz, et al. (2016) The 2016 revision to the World Health Organization (WHO) classification of myeloid neoplasms and acute leukemia. Blood 127: 2391-2405.

33. Pollyea DA, Kohrt HE, Yang J, Chang ET, Gomez SL, et al. (2014) Acute leukemia in adult Hispanic Americans: differences in incidence rates by nativity. J Cancer Prev Curr Res 1: 1-7. 


\section{Cancer Therapy \& Oncology International Journal}

34. Bacher U, Kern W, Schnittger S, Hiddemann W, Schoch C (2005) Further correlations of morphology according to FAB and WHO classification to cytogenetics in de novo acute myeloid leukemia: a study on 2235 patients. Ann Hematol 84(12): 785-791.

35. Buitrón-Santiago N, Arteaga-Ortiz L, Rosas-López A, Aguayo González Álvaro, López Karpovitch Xavier, et al. (2010) Experiencia del INCMNSZ en pacientes adultos con leucemia mieloide aguda. Cohorte 2003-2008. Rev Invest Clin 62(2): 100-108.

36. Jaime-Pérez JC, Brito-Ramirez AS, Pinzon-Uresti MA, Gutiérrez-Aguirre H, Cantú-Rodríguez OG, et al. (2014) Characteristics and clinical evolution of patients with acute myeloblastic leukemia in northeast Mexico: an eight-year experience at a university hospital. Acta Haematol 132: 144-151.

37. David Gómez-Almaguer, Edson Rene Marcos Ramirez, Efreen Horacio, Guillermo J, Carlos Roberto, et al. (2017) Acute Leukemia Characteristics are Different Around the World: the Mexican Perspective. Clinical Lymphoma Myeloma and Leukemia 17(1): 46-51.

38. de Jonge HJM, Valk PJM, de Bont ESJM, Schuringa JJ, Ossenkoppele G, et al. (2011) Prognostic impact of white blood cell count in intermediate risk acute myeloid leukemia: relevance of mutated NPM1 and FLT3 ITD. Haematologica 96(9): 1310-1317.

39. Choi Y, Lee JH, Kim SD, Kim DY, Lee JH, et al. (2013) Prognostic implications of CD14 positivity in acute myeloid leukemia arising from myelodysplastic syndrome. Int J Hematol 97 (2): 246-255.

40. Estey E, Döhner H (2006) Acute myeloid leukaemia. Lancet 368(9550): 1894-1907.

41. Lowenberg B, Ossenkoppele GJ, van Putten W, Schouten HC, Graux C, et al. (2009) High-dose daunorubicin in older patients with acute myeloid leukemia. N Engl J Med 361(13): 1235-1248.

42. Fernandez HF, Sun Z, Yao X, Litzow MR, Luger SM, et al. (2009) Anthracycline Dose Intensification in Acute Myeloid Leukemia. N Engl J Med 361(13): 1249-1259.
43. Padilha SL, Souza EJ dos S, Matos MCC, Domino NR (2015) Acute myeloid leukemia: survival analysis of patients at a university hospital of Paraná. Revista Brasileira de Hematologia e Hemoterapia 37(1): 2127.

44. Pulte D, Redaniel MT, Jansen L, Brenner H, Jeffreys M (2013) Recent trends in survival of adult patients with acute leukemia: overall improvements, but persistent and partly increasing disparity in survival of patients from minority groups. Haematologica 98(2): 222229.

45. Wang J, Yang YG, Zhou M, Xu JY, Ouyang J, et al. (2013) Meta-Analysis of Randomised Clinical Trials Comparing Idarubicin + Cytarabine with Daunorubicin + Cytarabine as the Induction Chemotherapy in Patients with Newly Diagnosed Acute Myeloid Leukaemia. PloS ONE 8(4): e60699.

46. de Jonge HJ, Valk PJ, de Bont ES, Schuringa JJ, Ossenkoppele G, et al (2011) Prognostic impact of white blood cell count in intermediate risk acute myeloid leukemia: relevance of mutated NPM1 and FLT3ITD. Haematologica 96(9): 1310-1317.

47. Vidriales MB, Pérez-López E, Pegenaute C, Castellanos M, Pérez JJ, et al. (2016) Minimal residual disease evaluation by flow cytometry is a complementary tool to cytogenetics for treatment decisions in acute myeloid leukaemia. Leuk Res 40: 1-9.

48. Bergua JM, Montesinos P, Martinez-Cuadrón D, Fernández-Abellán P, Serrano J (2016) A prognostic model for survival after salvage treatment with FLAG-Ida +/- gemtuzumab-ozogamicine in adult patients with refractory/relapsed acute myeloid leukaemia. $\mathrm{Br} \mathrm{J}$ Haematol 174(5): 700-710.

49. Keating S, Suciu S, de Witte T, Mandelli F, Willemze R, et al. (1996) Prognostic factors of patients with acute myeloid leukemia (AML) allografted in first complete remission: an analysis of the EORTCGIMEMA AML 8A trial. The European Organization for Research and Treatment of Cancer (EORTC) and the Gruppo Italiano Malattie Ematologiche Maligne dell' Adulto (GIMEMA) Leukemia Cooperative Groups. Bone Marrow Trasplant 17(6): 993-1001.

\section{Your next submission with Juniper Publishers} will reach you the below assets

- Quality Editorial service

- Swift Peer Review

- Reprints availability

- E-prints Service

- Manuscript Podcast for convenient understanding

- Global attainment for your research

- Manuscript accessibility in different formats

( Pdf, E-pub, Full Text, Audio)

- Unceasing customer service

Track the below URL for one-step submission https://juniperpublishers.com/online-submission.php 